\title{
Microstructure Characterization of Single and Multipass 13Cr4Ni Steel Welded Joints
}

\author{
Mohsen Mokhtabad Amrei ${ }^{1}$ Yves Verreman ${ }^{2}$ - Florent Bridier ${ }^{1}$ - Denis Thibault ${ }^{3}$. \\ Philippe Bocher ${ }^{1}$
}

Received: 13 January 2015/Revised: 26 March 2015/Accepted: 1 April 2015/Published online: 17 April 2015

(C) Springer Science+Business Media New York and ASM International 2015

\begin{abstract}
Cr} 4 \mathrm{Ni}$ martensitic stainless steels are frequently used in hydroelectric industries. Considering the size and geometry of the turbine runners manufactured in hydroelectric industries, multipass welding procedures are common methods for fabrication and repair. In this research, the microstructures and crystallographic textures of single-pass and double-pass welds have been studied as a first approach to understand a multipass weld. The highest hardness has been measured in the high-temperature heataffected zone (HAZ) inside the base metal. Similarly, it has been found that the heat of the second pass increases the hardness of the previous pass and produces a finer martensite microstructure. In areas of the HAZ, 3-6 mm from the fusion line, a tempering-like effect is reported; traces of austenite have also been found in these areas documenting the complexity of the microstructure found in the multipass welds.
\end{abstract}

Keywords Martensitic stainless steels - Flux-cored arc welding (FCAW) - 13Cr4NiMo steels $\cdot$ As-welded microstructure $\cdot$ Hardness $\cdot$ Martensite $\cdot \delta$-Ferrite . Heat-affected zone $\cdot$ Reversed austenite $\cdot$ Tempering

Mohsen Mokhtabad Amrei

mmokhtabad@gmail.com

École de Technologie Supérieure, Montreal, QC, Canada

2 École Polytechnique de Montréal, Montreal, QC, Canada

3 Institut de recherche d'Hydro-Québec, Varennes, Canada

\section{Introduction}

Low-carbon martensitic stainless steels such as $13 \mathrm{Cr} 4 \mathrm{Ni}$ steels are widely used in hydroelectric, power generation, offshore, and petrochemical industries, where high strength, toughness, and wear resistance of components are mandatory. Due to the size of the parts to be manufactured, welding processes are used for fabrication and repair despite the possible mismatch in mechanical properties of the body and the welded area [1]. To minimize the mismatch, 410NiMo flux-cored filler wire is used to produce weld metals with sufficient toughness as it has the same composition and its carbon content is lower than conventional martensitic stainless steels [2].

During solidification, $13 \mathrm{Cr} 4 \mathrm{Ni}$ steel solidifies to $\delta$-ferrite and starts to transform into austenite at around $1300{ }^{\circ} \mathrm{C}$. In thermodynamically equilibrium conditions, this transformation ends around $1200{ }^{\circ} \mathrm{C}$ [3]. However, due to the actual high cooling rates of the welding procedures, small amounts of $\delta$-ferrite can remain in the final microstructure at room temperature because of micro-segregation of alloying elements, during solidification [1]. At lower temperatures, the austenite transforms to martensite with small amounts of retained austenite between martensite laths [4-7]. Thus, after cooling down to room temperature, the microstructure is martensitic with potentially small amounts of $\delta$-ferrite and austenite.

Welded parts of $13 \mathrm{Cr} 4 \mathrm{Ni}$ are usually subjected to postweld heat treatments (PWHT) which consist of a single- or a double-stage tempering heat treatment. The goal of these heat treatments is to temper the fresh martensite formed during cooling. It has been shown that a proper PWHT can transform some martensite back to austenite in large amounts (up to 25\%) which influences mechanical properties [8]. However, this study focuses on non-heat-treated 
weld conditions to better understand their microstructure formation and characteristics. In particular, the work will focus on an adjacent weld pass which produces a local heat treatment in the already-solidified regions.

\section{Experimental Conditions}

Flux-cored arc welding (FCAW) process was used to deposit the weld beads on a steel substrate. Single-pass and doublepass welds were performed on a CA6NM plate using 13Cr4Ni flux-cored welding electrodes (E410NiMoT1-4) with a robotic welding machine and according to AWS A.5.22. Welding parameters are given in Table 1. Figure 1 shows the schematic cross sections of the single-pass and double-pass samples. The nominal composition of weld plate and the welding electrode are shown in Table 2.

The actual chemical compositions of the weld metal and base metal were measured by the glow discharge atomic emission spectrometers (except for $\mathrm{C}, \mathrm{N}, \mathrm{O}$, and $\mathrm{S}$ that were measured by combustion/fusion determination methods). Microstructure, chemical composition, hardness, and austenite percentage were determined in the as-welded conditions. Samples were polished and electro-polished with a solution of $65 \mathrm{ml} \mathrm{HClO}$, $550 \mathrm{ml}$ ethanol, $70 \mathrm{ml}$ butyl-cellusolve, and $70 \mathrm{ml} \mathrm{H}_{2} \mathrm{O}$ at $25{ }^{\circ} \mathrm{C}, 25 \mathrm{~V}$ for $20 \mathrm{~s}$ to reveal austenite particles. The volume fractions of the austenite in samples were measured by x-ray diffraction from a Rietveld analysis Diffractometer at Institut de Recherche d'Hydro-Québec (IREQ) [9]. Hardness evaluations have been done in the as-welded samples using a micro-hardness testing machine with a load of $200 \mathrm{~g}$ and a loading time of $10.2 \mathrm{~s}$. A scanning electron microscope (SEM) operated at $20 \mathrm{kV}$ was used to observe the microstructures of the samples. Electron backscatter diffraction (EBSD) maps were used to study the grain orientations of weld metal with Tango orientation map display and manipulation software.

\section{Chemical Compositions}

The chemical compositions of base metal and weld metal are given in Table 3. In the weld zone, compositions are close to the nominal composition of the consumable electrode. The low carbon content of the filler electrodes produced a low-carbon weld metal of about $\sim 0.023 \mathrm{wt} \%$ of carbon. Low carbon content produces high ductility of the weld metal and increases the fracture properties of the joint [2].

The chromium and nickel equivalent $\left(\mathrm{Cr}_{\mathrm{eq}}\right.$ and $\left.\mathrm{Ni}_{\mathrm{eq}}\right)$ can be calculated from the following Schaeffler formulae:

$\mathrm{Cr}_{\mathrm{Eq}}=\mathrm{Cr}+\mathrm{Mo}+1.5 \times \mathrm{Si}+0.5 \times \mathrm{Nb}$

$\mathrm{Ni}_{\mathrm{Eq}}=\mathrm{Ni}+30 \times \mathrm{C}+0.5 \times \mathrm{Mn}$.

The values for the weld metal of this study are $\mathrm{Cr}_{\mathrm{eq}}=12.79$ and $\mathrm{Ni}_{\mathrm{eq}}=5.36$.

Based on the Schaeffler diagram, a fully martensitic microstructure is expected as shown in Fig. 2. In fact, it stays very close to martensite- $\delta$-ferrite and martensiteaustenite regions. However, the Schaeffler diagram cannot predict the existence of delta-ferrite if segregation takes place [10], nor that of retained austenite if chemical diffusion takes place during long temperature exposure when some austenite is present in the microstructure [11].

\section{Microstructure of the Base Metal After Welding}

The base metal displays similar features for single- and double-pass welded samples. In the next sections, only the single-pass sample will be presented and discussed, but similar observations have been made on the double-pass sample.

The microstructure of a single-pass weld sample is shown in Fig. 3. Four distinctive zones can be seen in the microstructure: base metal, heat-affected zone (HAZ), high-temperature HAZ (HT-HAZ), and weld metal. As described by Carrouge, the thermal cycle of the weld produces more zones based on the steel phase diagram [12]; however, they cannot be differentiated in Fig. 3.

Base metal had a low resistance to the etchant as compared to the weld metal. A darker aspect is obtained due to the presence of carbides. The microstructure of base metal in regions unaffected by heat cycle consists of fine tempered martensite laths, as shown in Fig. 4 . $\delta$-ferrite phase appears in between martensite laths as bright white regions [13]. These regions can also be clearly found using band contrast images from EBSD measurements (Fig. 5) as, in

Table 1 Welding parameters

\begin{tabular}{llllllllll}
\hline Method & $\begin{array}{l}\text { Pre-heat } \\
\text { temp. }\left({ }^{\circ} \mathrm{C}\right)\end{array}$ & $\begin{array}{l}\text { Interpass } \\
\text { temp. }\left({ }^{\circ} \mathrm{C}\right)\end{array}$ & $\begin{array}{l}\text { Voltage } \\
(\mathrm{V})\end{array}$ & $\begin{array}{l}\text { Current } \\
(\mathrm{A})\end{array}$ & $\begin{array}{l}\text { Torch Speed } \\
(\mathrm{mm} / \mathrm{s})\end{array}$ & $\begin{array}{l}\text { Filler deposit } \\
\text { rate }(\mathrm{kg} / \mathrm{h})\end{array}$ & $\begin{array}{l}\text { Heat Input } \\
(\mathrm{J} / \mathrm{mm})\end{array}$ & $\begin{array}{l}\text { Welding } \\
\text { Position }\end{array}$ & $\begin{array}{c}\text { Gas } \\
\text { FCAW }\end{array} 180$ \\
\hline
\end{tabular}


Fig. 1 Schematic cross sections of (a) single-pass sample and

(b) double-pass sample (a) Single weld bead

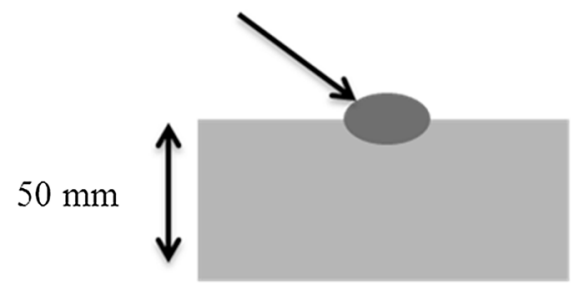

(b) Second weld bead

First weld bead

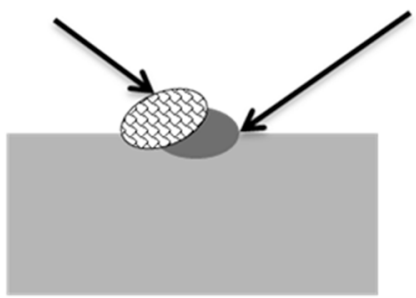

Table 2 Nominal composition of base metal and welding electrode (wt $\%$ )

\begin{tabular}{lllllllllll}
\hline Grade & Dimension & $\mathrm{C}$ & $\mathrm{Mn}$ & $\mathrm{P}$ & $\mathrm{S}$ & $\mathrm{Si}$ & $\mathrm{Cr}$ & $\mathrm{Ni}$ & $\mathrm{Mo}$ & $\mathrm{Cu}$ \\
\hline CA6NM & 5 cm thk. & $<0.06$ & $<0.5$ & $<0.04$ & $<0.03$ & $<0.1$ & $11.5-14$ & $3.5-4.5$ & $0.4-1.0$ & $<0.05$ \\
E410NiMoT1 & $1.6 \mathrm{~mm}$ dia. & 0.021 & 0.36 & 0.008 & 0.011 & 0.37 & 12.46 & 4.39 & 0.56 & 0.03 \\
\hline
\end{tabular}

Table 3 Chemical compositions of base metal and weld metal samples (wt\%)

\begin{tabular}{lllllllllll}
\hline Name & $\mathrm{C}$ & $\mathrm{Mn}$ & $\mathrm{P}$ & $\mathrm{S}$ & $\mathrm{Si}$ & $\mathrm{Cr}$ & $\mathrm{Ni}$ & $\mathrm{Mo}$ & $\mathrm{Al}$ & $\mathrm{N}$ \\
\hline CA6NM & 0.043 & 0.713 & 0.0267 & 0.0049 & 0.43 & 12.5 & 4.17 & 0.467 & 0.019 & $\ldots$ \\
Weld metal & 0.022 & 0.377 & 0.0099 & 0.0094 & 0.44 & 11.6 & 4.5 & 0.529 & 0.0136 & 0.00284 \\
\hline
\end{tabular}

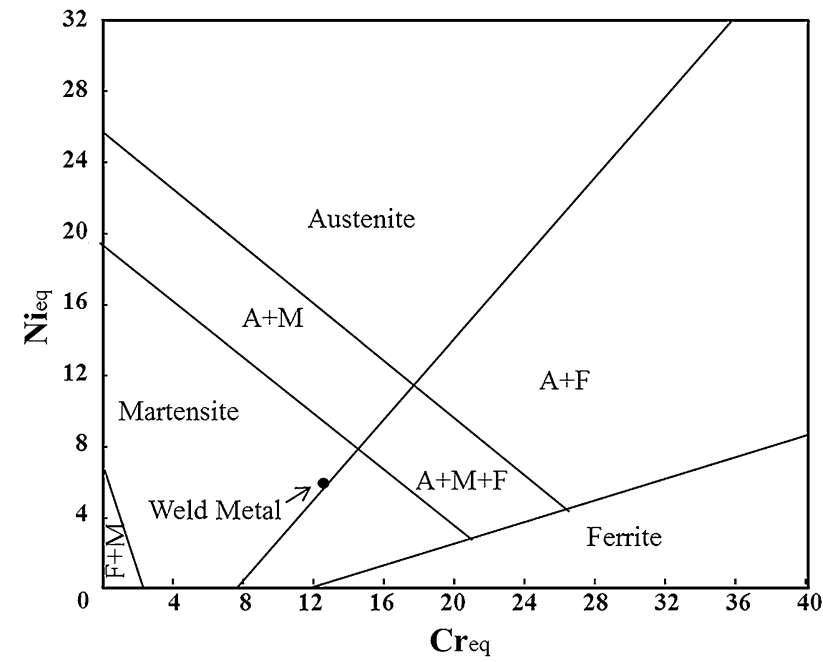

Fig. 2 Schaeffler diagram and microstructure prediction of the weld metal [1]

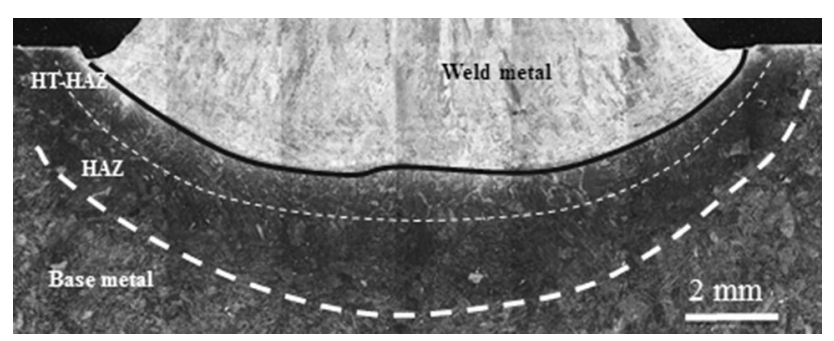

Fig. 3 Microstructure of a single-pass weld

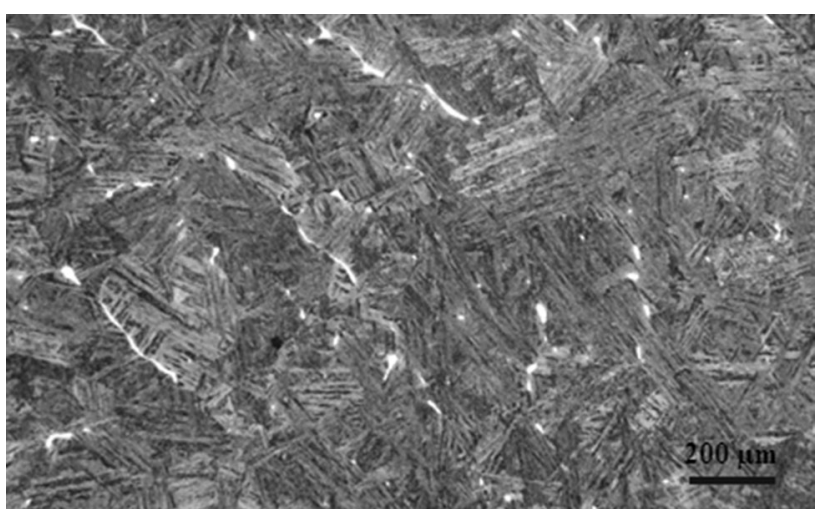

Fig. 4 Microstructure of the CA6NM steel (base metal consisting of tempered martensitic matrix and $\delta$-ferrite particles, etched by Vilella's reagent)

the etched image, $\delta$-ferrite appears as white particles. Image analysis showed $1.3 \%$ of $\delta$-ferrite phase with an average area size of $233 \mu \mathrm{m}^{2}$ and an average size of $22.6 \mu \mathrm{m}$. These ferrite grains are remnants from the casting procedure.

The HAZ region in the base metal is the darkest area around weld. It etches easily as carbides formation could happen due to weld thermal cycle [14]. Apart from becoming darker than the base metal when etched, there is no other detectable microstructure difference which can differentiate HAZ from base metal. Then it is difficult to define precisely the border between the unaffected base 
metal and HAZ. The HAZ seems 3 mm thick in Fig. 3, but it will be shown later that this distance is in fact about $6 \mathrm{~mm}$ based on hardness measurements.

The region of the first $500 \mu \mathrm{m}$ adjacent to the weld metal is called HT-HAZ (Fig. 3). It was exposed during welding to temperatures greater or equal to the $\delta$-ferrite transformation temperature. Between 300 and $500 \mu \mathrm{m}$ from the fusion line, parent austenite grain boundaries can be seen in the microstructure as they are underlined by chromium-rich bright regions (Fig. 6). These boundaries are more resistant to etching than martensite. Closer to the fusion line, a region of about $300 \mu \mathrm{m}$ in width displays the traces of dendritic-type microstructure. Black micro segregations can be found, marking the previous ferrite

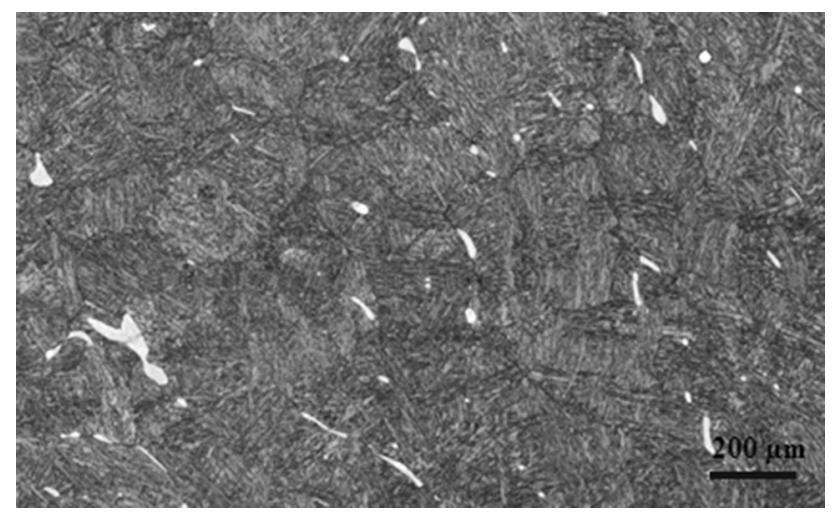

Fig. 5 EBSD band contrast image of the CA6NM steel (base metal) microstructure

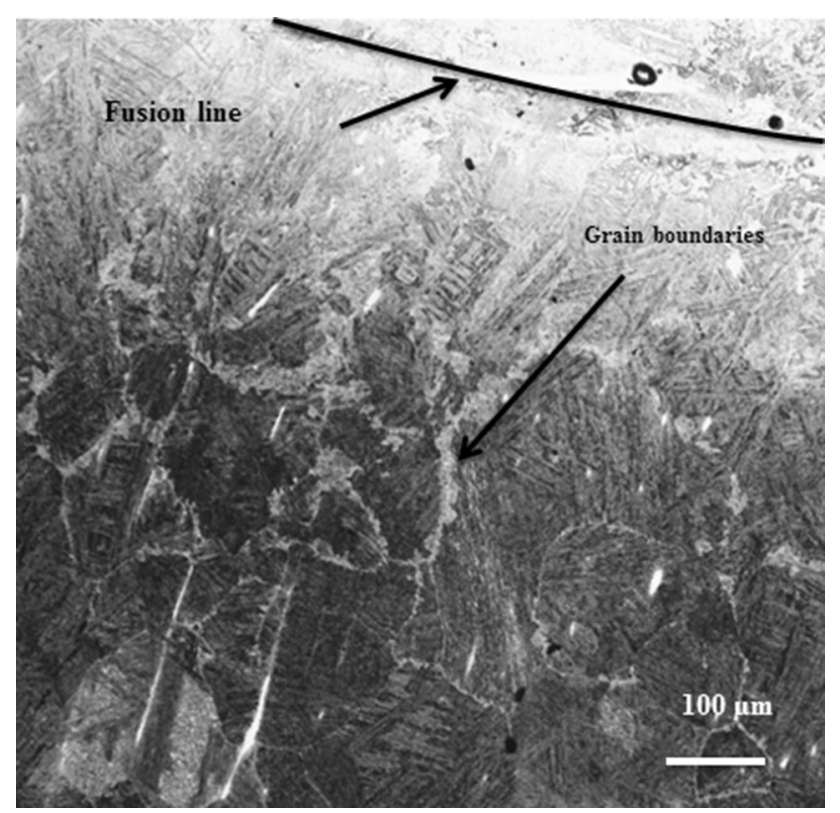

Fig. 6 Optical image of parent austenite grain boundaries underlined by bright phase in HT-HAZ (between 300 and $500 \mu \mathrm{m}$ from the fusion line) dendritic structures (Fig. 7). These structures document the fact that weld heat generated a semi-liquid region where the former ferritic structure of solidification was able to be reformed. The fusion line precise location was determined by the presence of plenty of micro-inclusions in the weld metal side as shown in the upper part of Fig. 7.

After a Kalling's etch together with EBSD maps of the HAZ, fine martensite microstructure was found in the HTHAZ (Fig. 8). This shows that the heat of the single pass produces a fine and fresh martensite microstructure in areas close to the fusion line. As one moves far from the fusion line, the martensite packets and laths appear more clearly suggesting that the temperature in these areas was just high enough to produce a partially fresh martensite microstructure.

\section{Microstructure of the Single-Pass Weld Metal}

In the single-pass weld metal sample, the microstructure can mostly be considered as fully martensitic. Although there are some evidence of inhomogeneities at the microscopic scale, such as former Widmanstatten austenite structures and $\delta$-ferrite dendrite segregations traces, no austenite has been found using XRD measurements or electropolishing technique.

After a Kalling's etching, about 5-mm-long columnar dendrites were found in the single-pass weld (Fig. 9). The grains display a general direction which suggests directional solidification perpendicular to the solid metal toward the top of the weld. EBSD maps were taken from the same location where Kalling's reagent had actually revealed crystalline orientation contrasts. Figure 10 documents an

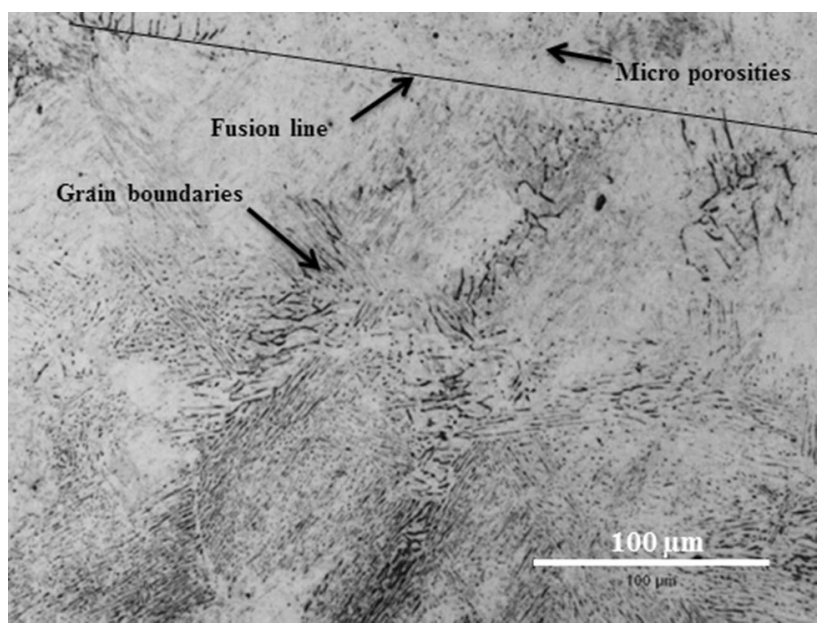

Fig. 7 Optical image of grain boundaries in HT-HAZ. Grain boundaries reformed $\delta$-ferrite segregations in areas close to the fusion line 
(a)

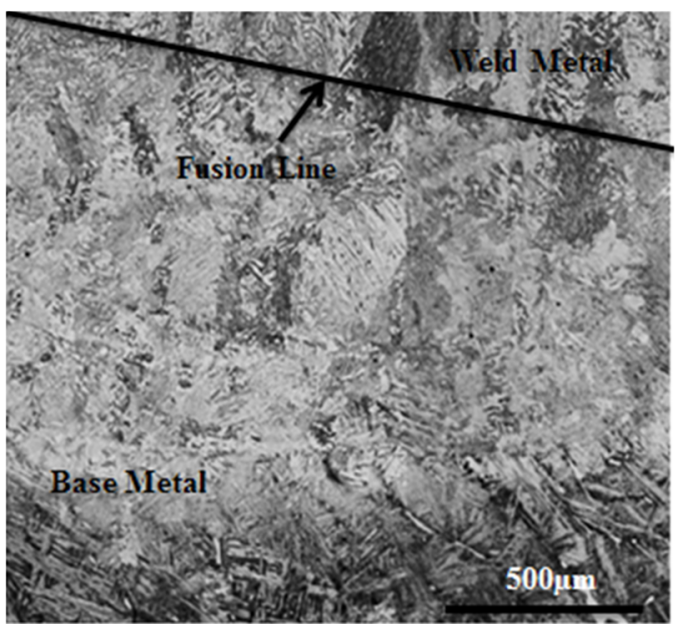

(b)

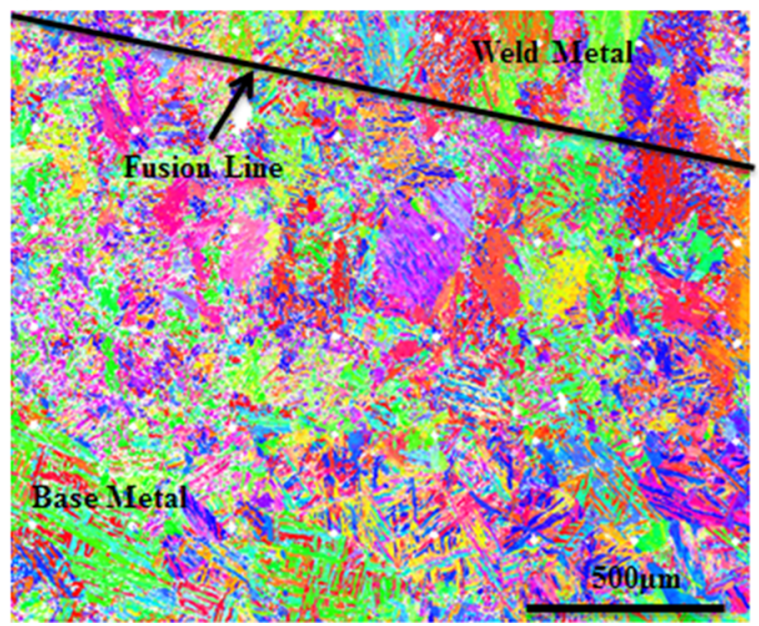

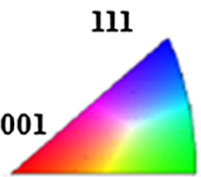

Fig. 8 (a) Microstructure of a HAZ region etched by Kalling's no. 2 reagent. (b) EBSD map of the same region. The welding direction is perpendicular to the image

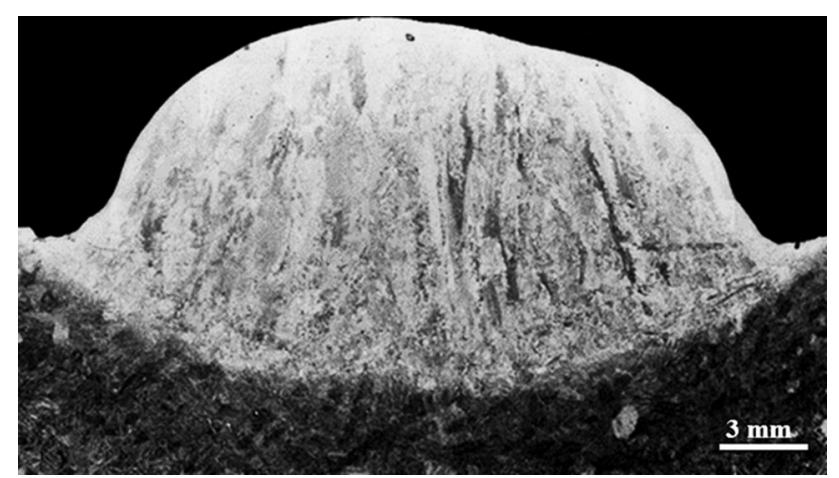

Fig. 9 Optical image of weld columnar growth in the single-pass weld metal

example of a good correspondence between EBSD orientation maps and etched microstructures.

The contrast resulting from the Kalling's etch is related to the various crystallographic orientations of the martensitic laths. These variations lead to different chemical activities in response to the chemical reagent and produce contrast in the metallography imaging. The large columnar microstructure observed macroscopically is actually the effect of a severe variant selection as most of the martensitic laths present in a grain have the same gray level, i.e., the same orientation. According to the various EBSD and Kalling's etch images obtained in the present work, only few martensite orientations are formed from the austenite grain. Moreover, as martensite laths do not pass from a grain to another, the columnar microstructure represents the austenite grain when very few variant selection is taking place [15]. Actually, the columnar-like martensite microstructure shows that severe variant selection has also been taking place during $\delta$-to- $\gamma$ transformation.
Former Widmanstatten austenite phase was found all over the weld inside columnar dendrites as shown in Fig. 11. Widmanstatten austenite was formed during the cooling of the ferrite phase and leaves traces like narrow wedges starting from former $\delta$-ferrite grain boundaries [12].

The traces of former $\delta$-ferrite dendrites are found close to the fusion line and at some places in the weld pool. These former $\delta$-ferrite dendrites are revealed by the presence of canyon-shaped structures resulting from the segregations of gammagene elements as seen in Fig. 12. This figure shows an example found in the middle of the weld pool as revealed by Kalling's reagent. Stronger segregation marks are found close to the fusion line. These $\delta$-ferrite dendrites usually stretch parallel to the fusion line as they are oriented by the flow of the molten metal. Figure 13(a) illustrates such a case using a SEM image. Actually, the negative of this image better displays the shape of the dendritic structure as illustrated in Fig. 13(b). These regions, about $300 \mu \mathrm{m}$ large, are chromium rich and have a relatively low content of iron as found by EDX (Fig. 13). The composition measurements have shown that these are alphagene regions in the weld and that the composition of the weld is not homogeneous. They could result from solidification segregations and $\delta$-ferrite particles from the base metal, or most probably from welding consumables partially dissolved in the weld pool.

\section{Microstructure of the Double-Pass Weld Sample}

The double-pass weld sample consists of two adjacent weld passes onto the plate (see Fig. 1). The microstructure of the second pass is very similar to that of the single-pass 
(a)

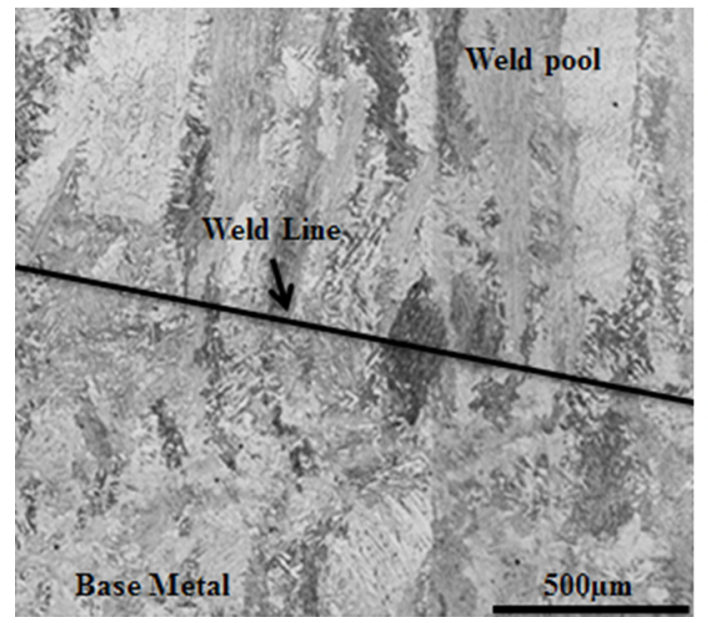

(b)

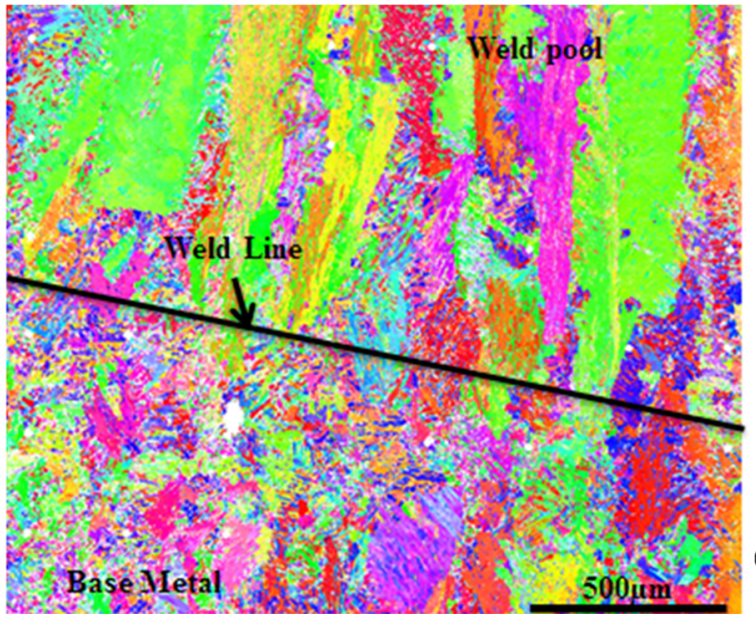

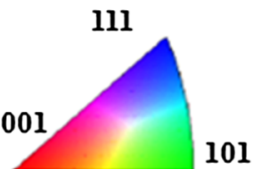

Fig. 10 Microstructure of the single-pass weld. (a) Etched by Kalling's no. 2 reagent. (b) EBSD map of the same region of weld presented in (a). The welding direction is perpendicular to the image

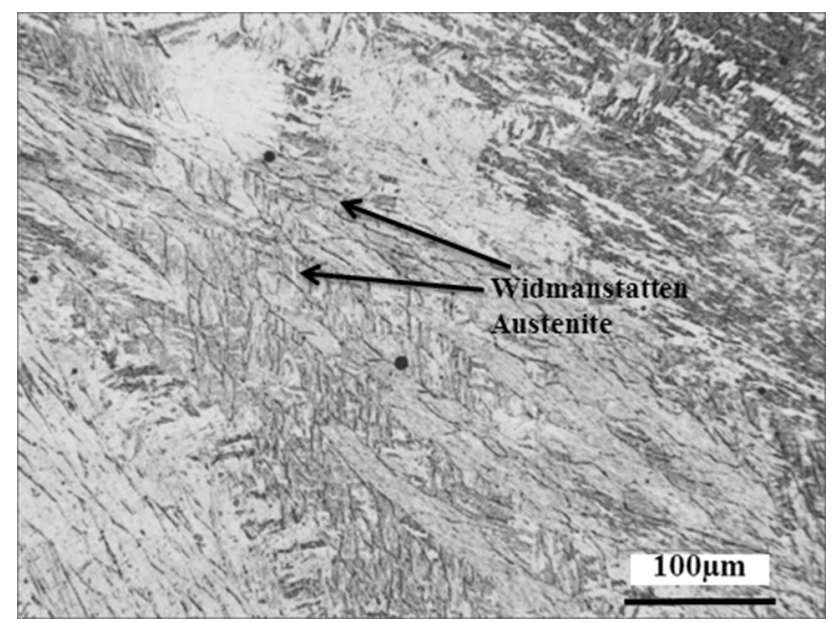

Fig. 11 Microstructure of the single-pass weld with traces of former Widmanstatten austenite microstructure. (Optical image of the etched sample)

specimen and will not be discussed in detail. Similarly, the base metal will not be discussed.

The first pass is affected by the heat of the second pass and could actually be considered as the HAZ of the second pass. In this case, the HAZ forms over the fresh martensite microstructure of the first pass and it has a hardness of about $340 \mathrm{HV}$. As a consequence, this HAZ is quite different from the HAZ formed in the base metal that was originally tempered martensite having hardness around 290 HV. Therefore, three distinctive regions can be observed on the optical image of first pass; HT-HAZ, intermediate-temperature-HAZ (IT-HAZ), and Tempered region (Fig. 14). It is worth mentioning that the position of the second pass fusion line could not be determined

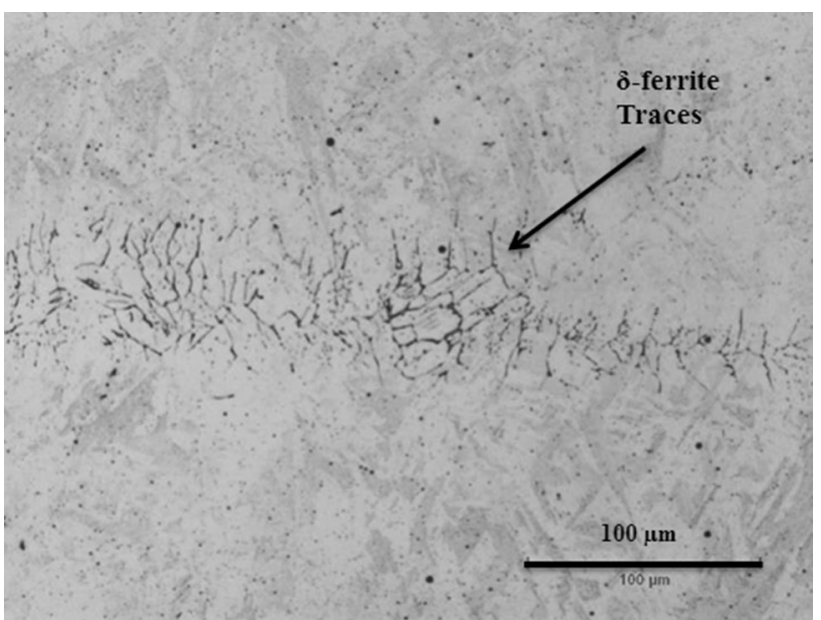

Fig. $12 \delta$-ferrite traces in the martensitic matrix of single-pass weld revealed by Kalling's etchant

precisely. In fact, the criterion used to define the position of the first pass fusion line was the different natures of porosities on both sides of the fusion line (small porosities in the weld metal, large ones in the base metal). As these defects are similar on both sides of the second pass fusion line, only the onset of columnar grains can be used as a criterion to define the second pass fusion line, and it makes the precision for the position of the second pass fusion line in the range of hundreds of micrometers.

The HT-HAZ has a fine martensite microstructure as revealed by the EBSD map shown in Fig. 15(a) and (b). The martensite laths of the first pass have been broken down into a finer microstructure. The thermal cycle of the second pass decreases the size of martensite laths in HTHAZ and more variants are formed. 

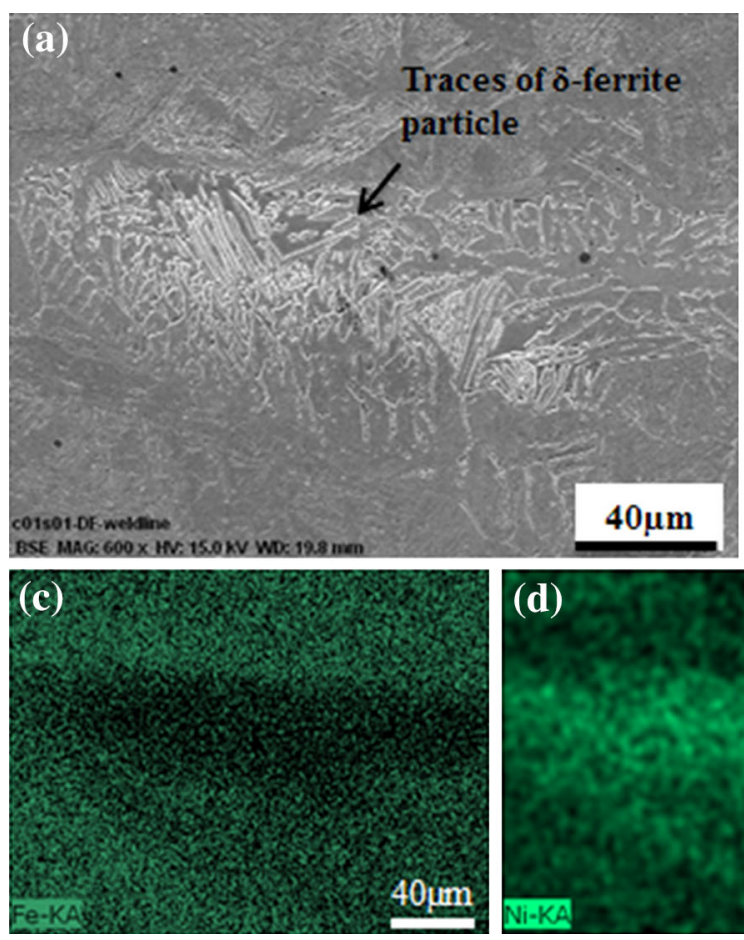
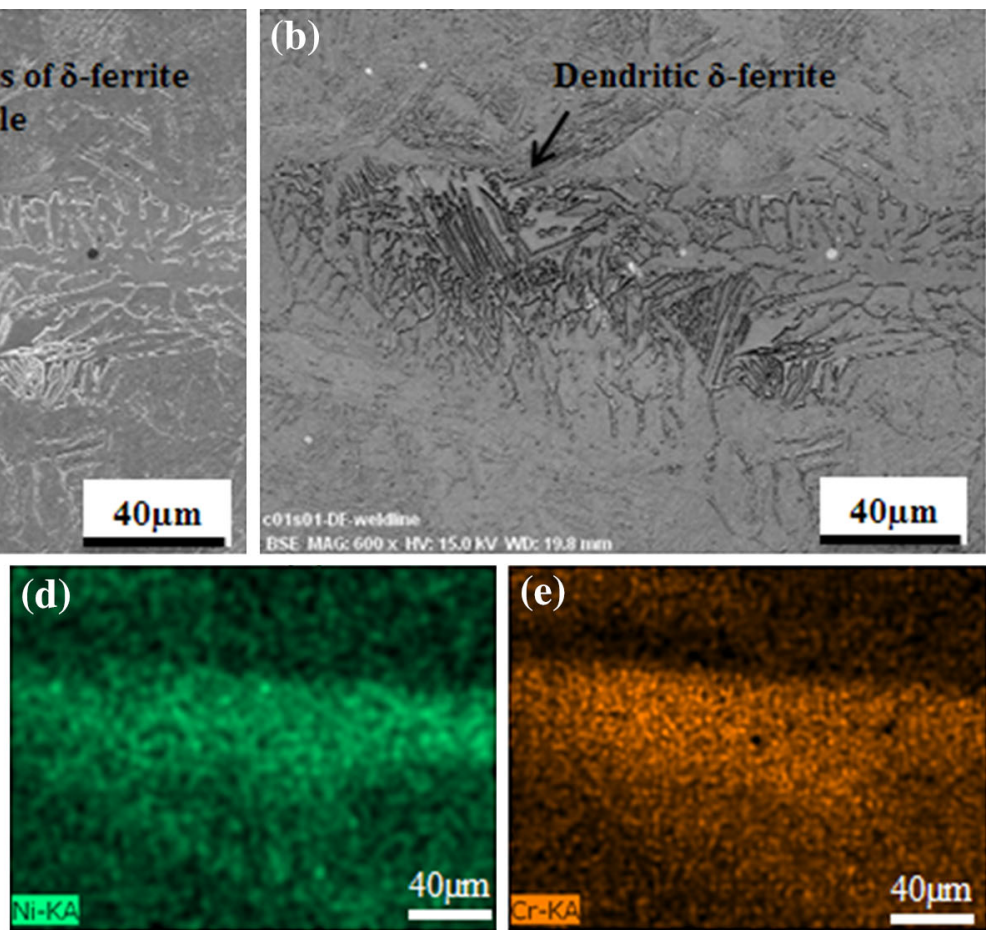

Fig. 13 SEM image and EDX maps of traces of former $\delta$-ferrite phase close to the fusion line. (a) SEM image of microstructure. (b) Negative image of (a) showing the dendritic structure of ferrites. (c)-(e) EDX spectroscopy of iron, nickel, and chromium in the same area of image (a)

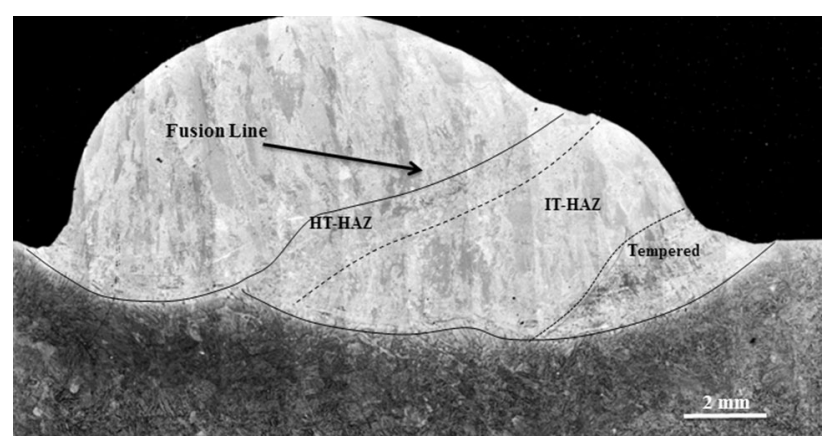

Fig. 14 Different regions in the first pass of a double-pass weld, based on microstructure observations

The IT-HAZ displays a microstructure similar to the initial single-pass microstructure, i.e., large martensite laths and columnar morphology stretching toward the top of the weld pass (compare to the lower part of Fig. 16). The heat of the second pass did not significantly affect the martensite structure, suggesting that similar variant selections are taking place in this region as in the single pass.

Tempered HAZ is located $3 \mathrm{~mm}$ away from the second pass and it is darker in the image, as seen in Fig. 14. This darker aspect is due to the formation of chromium and molybdenum carbides induced by the second pass $[12,16]$. Some probable traces of reformed austenite have been found in this area in accordance with the results of XRD measurements showing about $2 \%$ of austenite phase in the sample. They are seen as white filaments in images as illustrated in Fig. 17. No trace of austenite has been found in any other region of the weld. These austenite particles suggest that the second pass increased the temperature high enough and for a sufficiently long period of time to allow gammagene element diffusion to martensite boundaries and (re)form austenite. The local enrichment of gammagene elements in the microstructure generates regions with low $\mathrm{M}_{\mathrm{S}}$ values, allowing the locally formed austenite to be stable at room temperature [14].

\section{Hardness Maps}

In order to characterize the local properties of the weld and relate them to the microstructure variations identified in the previous sections, hardness maps have been measured on the single-pass and double-pass samples.

The hardness map of single-pass weld is shown in Fig. 18. The weld metal has almost uniform hardness with a mean hardness value of $350 \pm 7 \mathrm{HV}$ (the \pm sign shows the standard deviation and it serves the same purpose for the rest of the text). The HAZ of the single pass measured by hardness goes more than $6 \mathrm{~mm}$ deep into the base metal. A hardness higher than the mean hardness of the weld metal was used as a criterion to define the HT-HAZ. A 
(a)

(b)

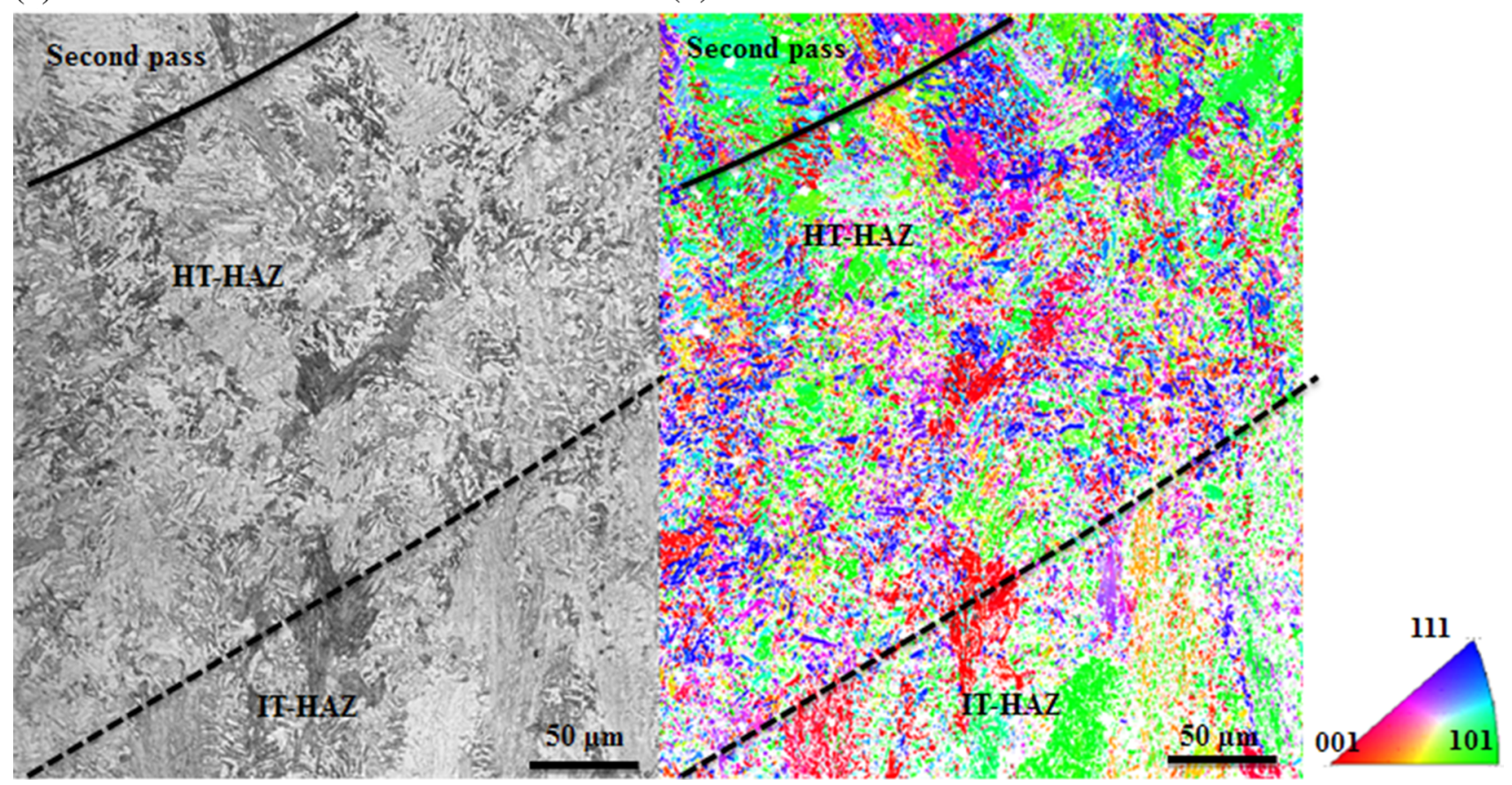

Fig. 15 Microstructure of HT-HAZ of double-pass sample. (a) Etched by Kalling's no. 2. (b) EBSD map of the same region of weld presented in (a)

(a)

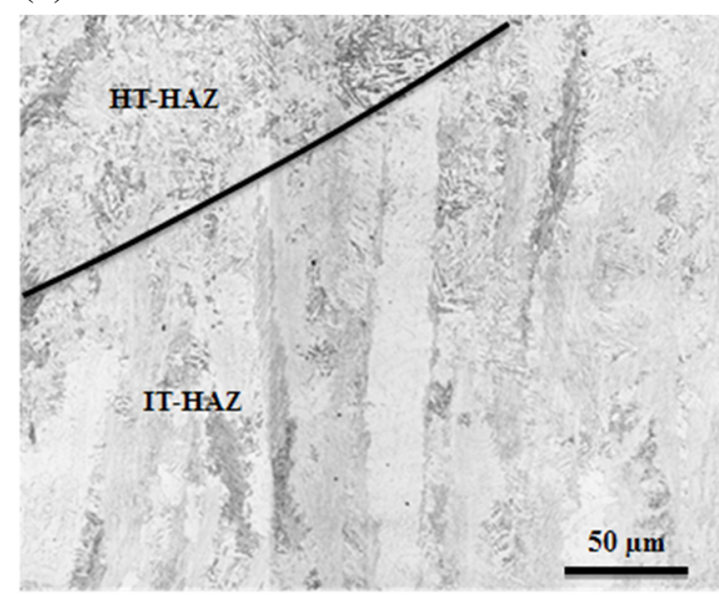

(b)

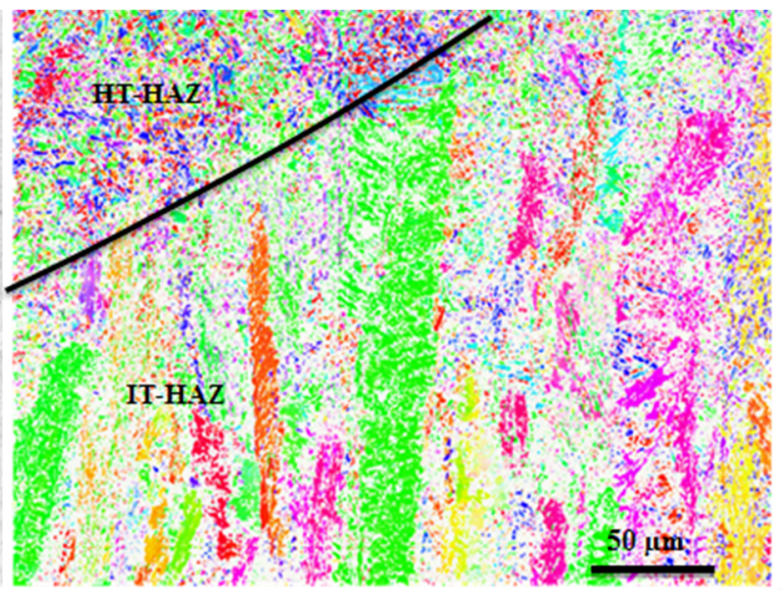

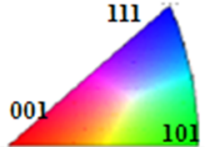

Fig. 16 Microstructure of IT-HAZ of double-pass sample. (a) Etched by Kalling's no. 2. (b) EBSD map of the same region of weld presented in (a)

region of about $1 \mathrm{~mm}$ deep with hardness up to $370 \pm 13 \mathrm{HV}$ was found. This corresponds to the region with fine microstructure, and the hardness measured is typical of fresh martensite in $13 \mathrm{Cr} 4 \mathrm{Ni}$ steels.

The boundary of the HAZ could be recognized as the area where the hardness values of HAZ decrease to the base metal hardness value which is about $290 \mathrm{HV}$. An area of lower hardness values was found before the HAZ boundary at $3 \mathrm{~mm}$ away from the fusion line. This area has hardness values only $10 \mathrm{HV}$ below the typical hardness of the base metal, but it illustrates the effect of the thermal cycle of the weld, which was sufficient to produce changes similar to a tempering heat treatment. The thermal cycle of the weld can not only over-temper the martensite of the base metal, but also form reversed austenite, resulting in low hardness values $[8,16,17]$. The hardness map of double-pass weld is shown in Fig. 19. The hardness map of the second pass is similar to the single-pass sample, but 


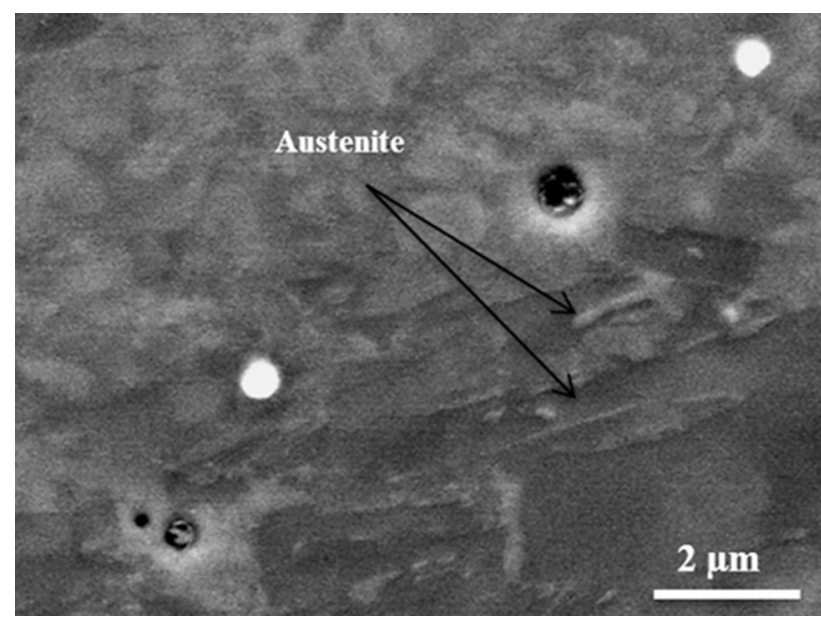

Fig. 17 FE-SEM image of austenite particles found in the tempered HAZ inside first weld due to the thermal cycle generated by the second pass

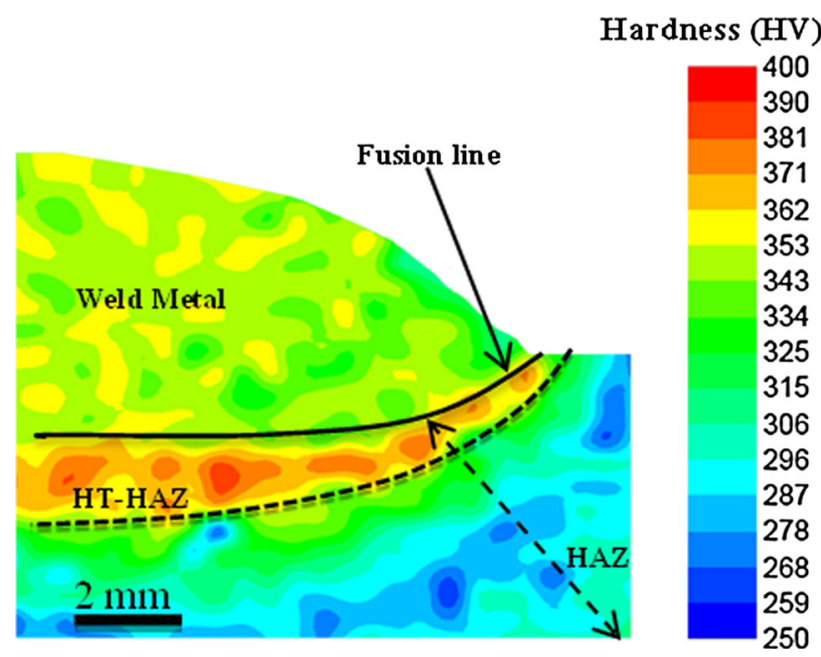

Fig. 18 2D Hardness map (HV) of the single-pass weld shown in Fig. 3 (2000 measurement points for a resolution of $150 \mu \mathrm{m}$ along horizontal and vertical directions)

with slightly higher values. As it is estimated by image analysis of the weld sample cross section, $25 \%$ of the actual composition of the first pass comes from the base metal, and then the composition of the first pass is different from the expected nominal composition of the electrode. This leads to higher Mn content and lower $\mathrm{N}$ and $\mathrm{S}$ percentages, showing lower hardness values [1]. Even if the second pass dissolves a significant amount of the first pass (about 20\% of dilution for the second pass is measured), the overall composition of the second weld is closer to that of the nominal electrode so that lower hardness is obtained. Actually, one can expect that the nominal composition will be obtained after several welded passes. The consequence of these composition variations is that lower hardness values could be expected in the weld passes closer to the base metal; however, as explained in the following section, there are other phenomena which can affect the above statement.

On the other hand, the HAZ introduced by the second pass in the first pass spreads over a $3 \mathrm{~mm}$ length with a mean hardness of $355 \pm 8 \mathrm{HV}$ which is $5 \mathrm{HV}$ higher than the original hardness of the single-pass weld. The heataffected distance is similar to the one induced by the single pass in the base metal, but the effect on the hardness level is different. The hardness values in the heat-affected region of single pass are rather homogenously distributed, and it is not possible to distinguish the presence of a HT-HAZ. The HT-HAZ can actually be only found based on a microstructure observation (This is related to fine martensite formation in HT-HAZ explained in Figs. 15 and 16). After this $355 \mathrm{HV}$ region, there is an area of lower hardness $(320 \pm 8 \mathrm{HV})$ which corresponds to the expected tempered region suggested by the microstructure examination (This is related to the darker region with the evidence of reformed austenite illustrated in Fig. 14).

The effects of the second pass on the first pass and its HAZ have been documented by making hardness measurements along two lines, one being taken in the singlepass sample and the other one in the same region in the double-pass sample (Fig. 20).

No effect on the hardness is seen beyond $6-7 \mathrm{~mm}$ from the fusion line (the HAZ of the first pass corresponds to zone (A) in Fig. 20). The first pass thermal cycle tempers the martensite present in the base metal at distances between 3 and $6 \mathrm{~mm}$. Microstructural evaluations showed that austenite particles were reformed in these regions where the $A c_{1}$ temperature of the base metal was reached. By moving toward the fusion line, the temperature reached by the weld thermal cycle is higher. The temperature increases until it becomes enough to transform some martensite back into austenite for a sufficient time to chemically stabilize it by gammagene elements diffusion.

The HAZ hardness increases at a distance less than $3 \mathrm{~mm}$ from the fusion line. In this region, the amount of reformed austenite is so high that no gammagene element enrichment is possible and fresh martensite is found at room temperature. Fresh martensite is responsible for the high hardness in this region. On the metallography sections (Fig. 10), it can be seen that the initial lath structure of the base metal martensite is replaced by an austenite parent grain-like structure.

The hardness reaches a maximum of $380 \pm 11 \mathrm{HV}$ at about $500 \mu \mathrm{m}$ from the fusion line. This peak of hardness corresponds to the location where the temperature was high enough to transform all martensite back into austenite which led the microstructure to be fresh martensite after cooling. 

double-pass weld sample showing the different regions (Same resolution as Fig. 18)
Fig. 19 Hardness map of

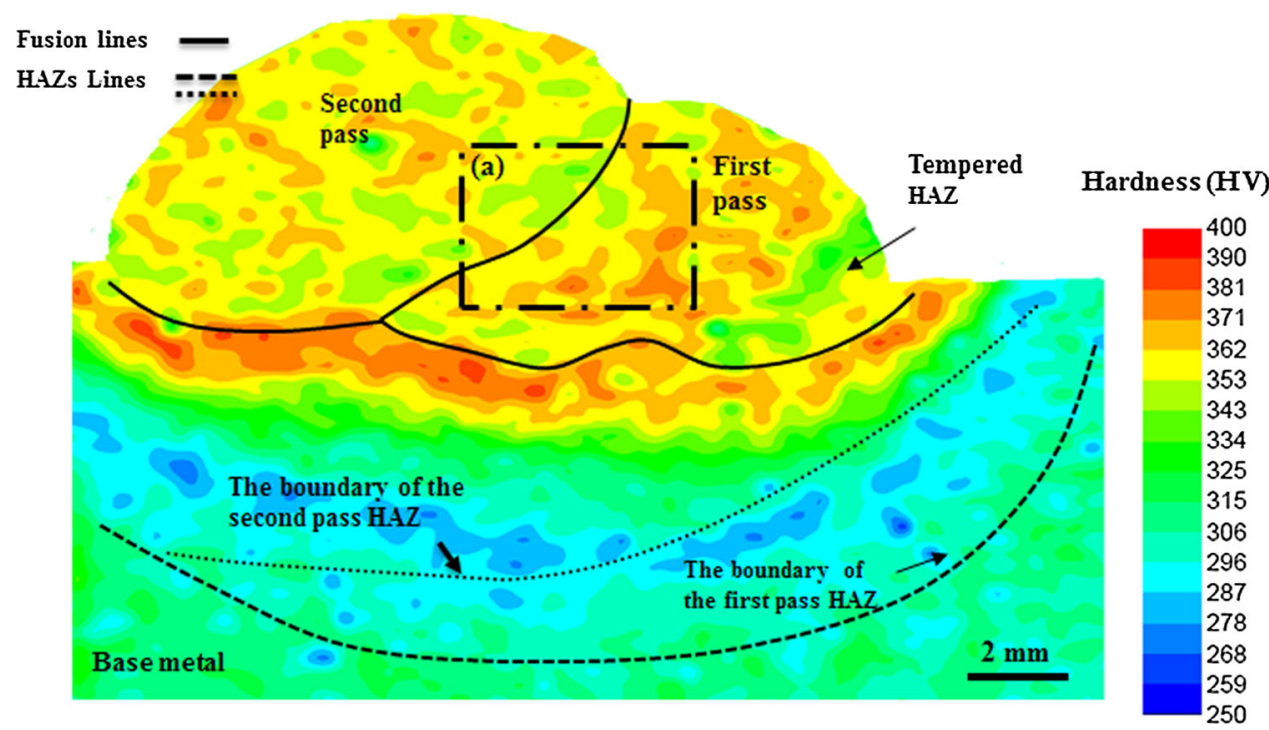

Fig. 20 Linear hardness measurements from the first pass fusion line. The upper right inset shows the schematic positions of the regions used for these measurements in (a) the single-pass sample and (b) the double-pass sample

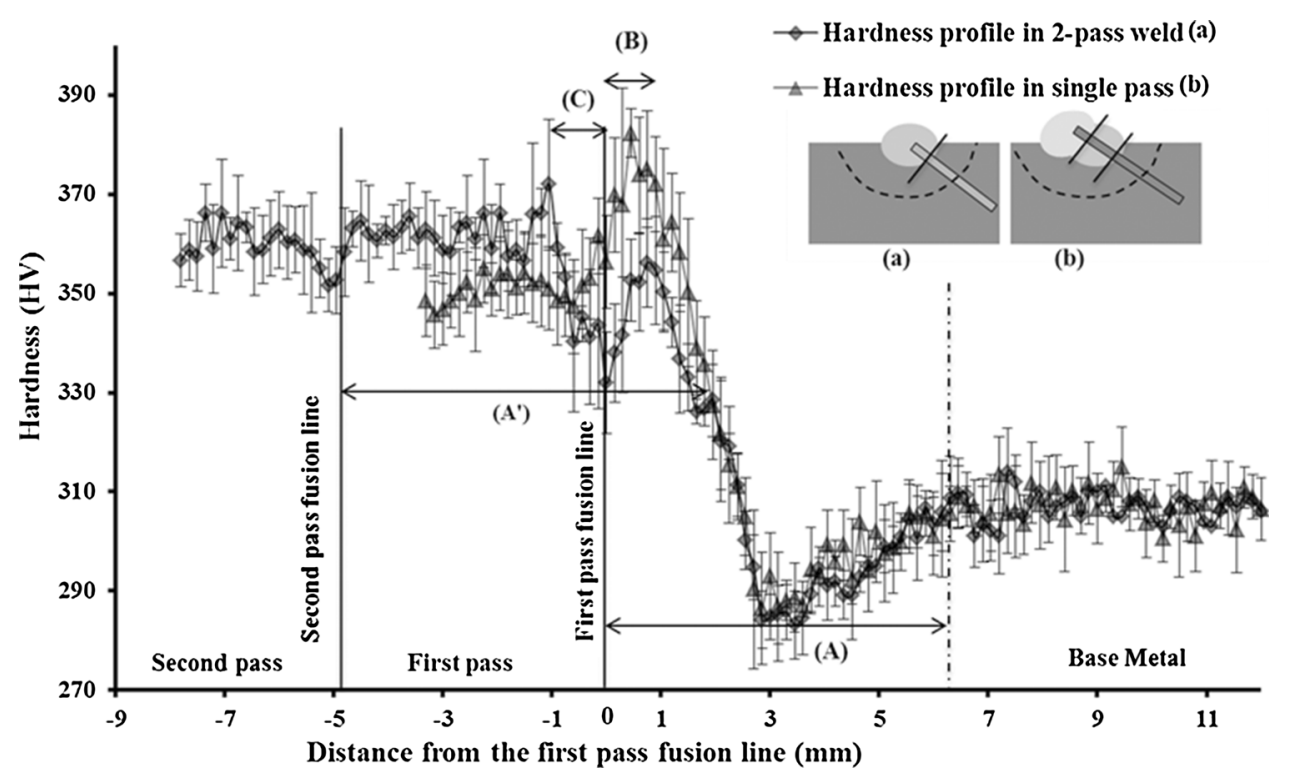

Lower hardness was measured between the hardness peak and the fusion line (See zone (B) in Fig. 20). This corresponds to the region where $\delta$-ferrite traces were found (Fig. 7). The very high temperature in this zone transforms some austenite into $\delta$-ferrite, producing a slightly softer matrix. Retained ferrite is expected to be softer than fresh martensite, resulting in lower hardness.

In the weld, the hardness decrease continues for the first $1 \mathrm{~mm}$ (See zone (C) in Fig. 20). In this zone too, traces of $\delta$-ferrite were found (Figs. 12, 13). These traces are $\delta$ ferrite phases of the base metal which consumed partially in the semi-solid region of the weld metal and they had not enough time to mix thoroughly with the weld metal. These unmixed phases generate complex microstructures with a local composition that is an intermediate composition between the base metal and the weld metal. The rest of the weld at the left presents a relatively homogeneous hardness of about $350 \mathrm{HV}$ which is a typical hardness of fresh martensite microstructure.

As for the effect of the double-pass weld, one can see that the heat effect of the second pass does not extend beyond 6-7 $\mathrm{mm}$ from its fusion line (zone $\mathrm{A}^{\prime}$ in Fig. 20). This is coherent with what was observed for a single-pass HAZ. A drop in hardness occurred at 3-6 mm away from the second pass fusion line. This drop is the tempering effect of the second pass similar to what has been found in the same distance from the fusion line of the first pass. The hardness of the first pass was increased of about $10 \mathrm{HV}$ after receiving heat from the second pass in areas $3 \mathrm{~mm}$ from the fusion line and closer. In these areas, some fresh 


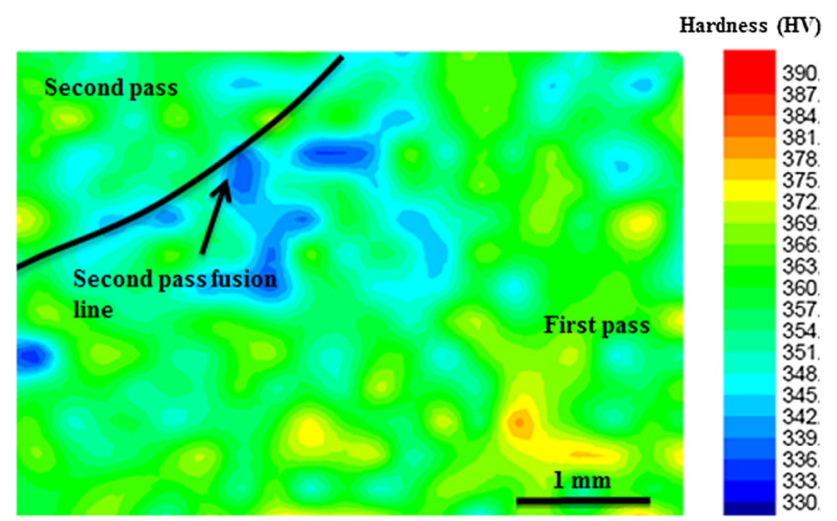

Fig. 21 Part of the hardness map of double-pass weld sample close to the second fusion line

martensitic microstructure forms over the fresh martensitic microstructure of the first pass with a similar circumstance/ mechanism to what has been reported in the single pass in the first $3 \mathrm{~mm}$. This double-quenched martensite forms finer martensitic packets within the grains and more carbides [18]; then it is expected to be harder than a one-time fresh martensite.

A small drop in hardness was seen close to the second pass fusion line. However, as explained earlier, the location of the second pass fusion line could not be precisely specified based on metallographic observation. One can assume that this drop is found before the fusion line due to the formation of $\delta$-ferrite in the double-quenched martensite matrix. The present authors propose to use this hardness drop as a more precise criterion to determine the second fusion line. This hardness drop can only be seen on precise hardness profiles and was not captured on the $2 \mathrm{D}$ hardness maps shown in Fig. 19 unless a more suitable color scale is used. An adapted color scale for frame (a) in Fig. 19 ranging from 330 to $390 \mathrm{HV}$ can reveal the fusion line as displayed in Fig. 21.

The linear hardness profiles in Fig. 20 show that the second pass hardness is higher than the hardness of the aswelded single pass. The lower Mn content and the higher $\mathrm{N}$ percentages in the second pass could explain this difference. It can be predicted that a multipass procedure may improve the hardness uniformity of the welded joint if extending similar effects of the second pass to several passes.

If the decrease of the maximum hardness peak value is related to tempering effects induced by the second pass, the hardness increase on the first $3 \mathrm{~mm}$ of the HAZ of the second pass can be a consequence of the double quenching of the microstructure in this region. Double quenching is known to increase martensite dislocation density, promote carbides coarsening, and increase crystallography variant selections, which eventually produces harder martensite $[18,19]$. The region that was originally fresh martensite as a part of the first pass weld metal is re-austenitized by the second heating/quenching sequence induced by the second pass. The second pass rises up the temperature higher than $A c_{1}$ at distances closer than $3 \mathrm{~mm}$ from the second pass fusion line resulting in a significant increase in hardness.

The present work showed that the second pass seems to homogenize the hardness of the built-up structure with a smoother transition between the base metal and the weld passes. However, one can wonder how additional passes could affect the microstructure and hardness distribution which will be presented by authors in a different article, and further research will be made in this direction.

\section{Conclusions}

The heat cycle of the weld produces heat-affected regions $6 \mathrm{~mm}$ deep into the base metal. The closest region to the weld line exhibits the hardness peak at its $500 \mu \mathrm{m}$ from the fusion line. Traces of dendritic $\delta$-ferrite were found, confirming that high temperatures were achieved during the weld deposition close to fusion line. Farther in the base metal, the heat cycle produces a microstructure which is the mixture of fresh martensite and tempered martensite from $500 \mu \mathrm{m}$ to $3 \mathrm{~mm}$. The regions farther than $3 \mathrm{~mm}$ from the fusion line exhibit the low hardness of the base metal-tempered martensite.

In $13 \mathrm{Cr} 4 \mathrm{Ni}$ weld metal, columnar grain microstructure filled with fine martensite laths was observed. It has been observed that most of this columnar macrostructure from the first pass does not change by the heat cycle of the second pass. This finding which has been confirmed by the images produced from etched samples with Kalling's no. 2 reagent revealed the same features as the maps from the EBSD. It has been shown that the heat of the second pass increases the mean hardness of the first pass but tempers the regions farther than $3 \mathrm{~mm}$ from its weld line resulting in softening of the previous pass HAZ. In some regions of the HAZ, the thermal cycle exposed by the second pass transforms the fresh martensite microstructure into austenite. The results showed that a multipass weld procedure produces a relatively more uniform hardness profile in the welded joint compared to a single-pass procedure.

Acknowledgments The authors would like to acknowledge Natural Sciences and Engineering Research Council of Canada (NSERC), Institut de Recherche d'Hydro-Québec (IREQ), Alstom Power, and École de Technologie Supérieure (ÉTS) for the technical and financial support. The authors are grateful to IREQ laboratory for the Rietveld analyses and metallography studies and to Dr. Pierre Hovington for the SEM studies.

\section{References}

1. J.C. Lippold, D.J. Kotecki, Welding Metallurgy and Weldability of Stainless Steels (Wiley, Hoboken, 2005) 
2. H. Zheng, X.N. Ye, J.D. Li, L.Z. Jiang, Z.Y. Liu, G.D. Wang, B.S. Wang, Effect of carbon content on microstructure and mechanical properties of hot-rolled low carbon $12 \mathrm{Cr}-\mathrm{Ni}$ stainless steel. Mater. Sci. Eng. A 527, 7407-7412 (2010)

3. E. Folkhard, Welding Metallurgy of Stainless Steels (Springer, Berlin, 1988)

4. W. Wu, L.Y. Hwu, D.Y. Lin, J.L. Lee, Relationship between alloying elements and retained austenite in martensitic stainless steel welds. Scripta Mater. 42, 1071-1076 (2000)

5. G.F.V. Voort, Martensite and retained austenite. Ind. Heat. 76, 51-54 (2009)

6. M.C. Tsai, C.S. Chiou, J.S. Du, J.R. Yang, Phase transformation in AISI 410 stainless steel. Mater. Sci. Eng. A A332, 1-10 (2002)

7. D. Thibault, P. Bocher, M. Thomas, J. Lanteigne, P. Hovington, P. Robichaud, Reformed austenite transformation during fatigue crack propagation of $13 \% \mathrm{Cr}-4 \% \mathrm{Ni}$ stainless steel. Mater. Sci. Eng. A 528, 6519-6526 (2010)

8. P.D. Bilmes, C. Llorente, J. PerezIpina, Toughness and microstructure of $13 \mathrm{Cr} 4 \mathrm{NiMo}$ high-strength steel welds. J. Mater. Eng. Perform. 9, 609-615 (2000)

9. H.M. Rietveld, A profile refinement method for nuclear and magnetic structures. J. Appl. Crystallogr. 2, 65-71 (1969)

10. P. Wang, S.P. Lu, N.M. Xiao, D.Z. Li, Y.Y. Li, Effect of delta ferrite on impact properties of low carbon $13 \mathrm{Cr}-4 \mathrm{Ni}$ martensitic stainless steel. Mater. Sci. Eng. A 527, 3210-3216 (2010)
11. X.D. Wang, B.X. Huang, Y.H. Rong, L. Wang, Microstructures and stability of retained austenite in TRIP steels. Mater. Sci. Eng. A 438-440, 300-305 (2006)

12. D. Carrouge, Phase transformations in welded supermartensitic stainless steels, Ph.D., University of Cambridge, 2002

13. W.S. Rasband, ImageJ, U.S. National Institutes of Health, 1997-2012

14. D. Thibault, P. Bocher, M. Thomas, Residual stress and microstructure in welds of $13 \% \mathrm{Cr}-4 \% \mathrm{Ni}$ martensitic stainless steel. J. Mater. Process. Technol. 209, 2195-2202 (2009)

15. D.A. Porter, Phase Transformations in Metals and Alloys (Chapman and Hall, London, 1996), p. 441

16. Y. Song, X. Li, L. Rong, Y. Li, The influence of tempering temperature on the reversed austenite formation and tensile properties in $\mathrm{Fe}-13 \% \mathrm{Cr}-4 \% \mathrm{Ni}-\mathrm{Mo}$ low carbon martensite stainless steels. Mater. Sci. Eng. A 528, 4075-4079 (2011)

17. P.D. Bilmes, M. Solari, C.L. Llorente, Characteristics and effects of austenite resulting from tempering of $13 \mathrm{Cr}-\mathrm{NiMo}$ martensitic steel weld metals. Mater. Charact. 46, 285-296 (2001)

18. G.E. Totten, Steel Heat Treatment Metallurgy and Technologies (Taylor and Francis, Portland, 2007), p. 832

19. J.F. Lancaster, Metallurgy of Welding, 6th edn. (Woodhead Publishing, Cambridge, 1999), p. 339 